\title{
In vitro and In silico Approaches to Study the Bioactivity of Citrus limon Leaf Extracts
}

\author{
Raji P1 ${ }^{1}$, Antony V Samrot ${ }^{1 *}$, Divya Dharani ${ }^{1}$ and Boniface Alexander ${ }^{2}$ \\ 'Department of Biotechnology, Sathyabama University, Jeppiaar Nagar, Chennai 119, Tamil Nadu, INDIA. \\ ${ }^{2}$ Department of Bioinformatics, Sathyabama University, Jeppiaar Nagar, Chennai 119, Tamil Nadu, INDIA.
}

\begin{abstract}
Aim: To study the bioactivity of Citrus limon leaf extracts through in vitro and in silico approaches. Methodology: In this study, the leaves of Citrus limon were subjected to solvent extraction using ethyl acetate and ethanol, and also the essential oil by hydro distillation method. Preliminary phytochemical screening of solvent extracts revealed the presence of alkaloids, flavanoids, anthocyanins, carbohydrates, triterpenoids, tannins and coumarins. The extracts and essential oil were then tested for the antibacterial, antioxidant and anticancer activity. Molecular docking studies were studied for the proteins namely tyrosine phosphatase, alkaline protease, and elastase of Pseudomonas aeruginosa whose protein structure retrieved from the PDB using discovery studio 2.0 version and inhibition was checked against all the three proteins. Results: The plant extract was found to inhibit the growth of Microvirga aerilata and Pseudomonas aeruginosa at $100 \mu \mathrm{g}$ and $50 \mu \mathrm{g}$ of essential oil and ethanol extract respectively. Cytotoxicity against HeLa cell lines by the crude extracts and essential oil
\end{abstract}

appeared to be active at the concentration of $50 \mu \mathrm{g} / \mathrm{mL}$ and $100 \mu \mathrm{g} / \mathrm{mL}$ respectively. GCMS studies on the essential oil revealed the presence of $\alpha$-pinene, $\beta$-pinene, decanal, citral and $\alpha$-terpineol. Molecular docking studies revealed that tyrosine phosphatase to interact better than the other two proteins.

Key words: Citrus limon, Phytochemical, Essential oil, Molecular docking. Correspondence :

Dr.Antony V Samrot, Associate Professor, Department of Biotechnology, Sathyabama University, Chennai, Tamil Nadu - 600119, INDIA.

Phone no: +9144-24503145

E-mail: antonysamrot@gmail.com

DOI: 10.5530/jyp.2017.9.57

\section{INTRODUCTION}

For a longer period of time, plants have been a larger and valuable source of natural products. The Indian system of medicine uses plant based drugs or formulations to treat human disease. These naturally occurring medicinal plants contain components which have therapeutic values. Plant extracts used in traditional medicines provide health coverage for most world's population. Essential oils and extracts of the medicinal plants gained a great scientific interest because of their wide range of organic compounds which include alkaloids, flavanoids, tannins, saponins, terpenoids, phenolic compounds etc. ${ }^{1}$ Citrus limon commonly known as lemon is a fruit of small evergreen tree which belongs to the family Rutaceae $^{2}$ usually seen growing in the tropical and sub-tropical areas. Citrus limon is the plant taken for our study as it has great economic value due to its use in food and pharmaceutical industries as flavouring agents, antioxidants and preservatives. Further the essential oils from the plant are used in aromatherapy to cure various disorders. All parts of this plant are used in the day to day life the fruits for instance is a good source of vitamin $\mathrm{C}$, and also as bleaching agent in domestic practice, as cleansing agent in cosmetic industry and also as non-toxic pesticide. Lemon tree flowers have been used as a remedy for the treatment of mild depression, sedation and heart tonic. Further they do exhibit anti-oxidant, anticoagulant, anticancer and antimicrobial activities. ${ }^{3-6}$ This plant possessing a multitude utility could be well exploited for its phytoconstituent responsible for the activity and characterized for the biosafety level which later could be developed into a value added commercial product.

\section{MATERIALS AND METHODS}

\section{Sample Collection}

Citrus limon leaves were collected from Tiruchirappalli, Tamil Nadu, India, were washed thrice with running tap water and shade dried. The dried leaves were powdered and stored till extraction.

\section{Preparation Of The Extract}

Extraction was done with two different solvents individually. $10 \mathrm{~g}$ of plant powder was macerated with the respective solvents. The liquid was clarified by filtration and then concentrated. Essential oil was also extracted by hydro-distillation method. ${ }^{7}$ The two different solvent extracts and the essential oil were stored at $4^{\circ} \mathrm{C}$ till further analysis.

\section{Phytochemical Analysis}

Chemical tests for the screening and identification of bioactive chemical constituents in the medicinal plant Citrus limon was carried out using the standard procedures. ${ }^{8-9}$

\section{Antibacterial Activity}

The in vitro antibacterial activity of the plant extracts and essential oil were evaluated by well diffusion method against Bacillus subtilis and Brevibacillus brevis and also against two gram negative organisms Psuedomonas aeruginosa and Microvirga aerilata. The extracts and essential oil were tested for four different concentrations viz.,20 $\mu \mathrm{g}, 40 \mu \mathrm{g}$, $60 \mu \mathrm{g}$ and $80 \mu \mathrm{g}$ and also for the essential oil by well diffusion method. Gentamicin was used as positive control and the respective solvent was used as negative control. Antibacterial activity was evaluated by measuring the inhibition of bacterial growth around the wells as zone of inhibition in $\mathrm{mm}$. 


\section{Determination Of Minimum Inhibitory Concentration}

Minimum inhibitory concentrations (MICs) of the samples were tested by the standard procedures..$^{10}$ Concentration ranging from 20 to $180 \mu \mathrm{g} / \mathrm{mL}$ was taken for the study. The plates were incubated at $37^{\circ} \mathrm{C}$ for $24 \mathrm{~h}$ and the tubes were examined for turbidity and MIC values were taken as the lowest concentration that inhibited the growth of the tested organisms.

\section{Radical Scavenging Activity}

Radical scavenging activity of the different fractions was determined using DPPH radical as a reagent ${ }^{11}$ with some modifications. After dark incubation of different concentration of extracts with DPPH the scavenging capacity was read colorimetrically by monitoring the decrease in absorbance at $517 \mathrm{~nm}$. Lower absorbance of the reaction mixture indicates high free radical scavenging activity. Ascorbic acid was used as the standard. ${ }^{12}$

$\mathrm{DPPH}$ radical scavenging activity $(\%)=[(\mathrm{A} 0-\mathrm{A} 1) /(\mathrm{A} 0)] \times 100$

A0, the absorbance of the control (DPPH radical + methanol); A1, the absorbance of sample (DPPH radical + sample or standard). The effective concentration required to scavenge $50 \%$ of the DPPH radical $\left(\mathrm{IC}_{50}\right)$ is also calculated.

\section{Cytoxicity Evaluation}

HeLa Cell lines were obtained from National center for cell sciences, Pune (NCCS). The cellular toxicity of the extracts was tested against the HeLa cells by MTT assay. ${ }^{13}$ The effect of the samples on the proliferation of HeLa cells was expressed as the \% cell viability, which was calculated as below: ${ }^{14}$

$\%$ cell viability $=$ mean OD of wells treated with plant extract $/$ mean OD of control wells $\times 100 \%$

\section{Separation Of Bioactive Compounds By Thin Layer Chromatography}

The extracts were subjected to thin layer chromatography (TLC) as per conventional one dimensional ascending method using silica gel. Suitable solvent system comprising of Acetone, Chloroform and Ethyl acetate in appropriate proportions were chosen for the study. The movement of the active compound was expressed by its retention factor $\left(R_{\mathrm{f}}\right){ }^{15}$

\section{Identification Of Compounds By Gc-Ms Analysis}

The active chemical constituents of the Citrus limon plant extract and essential oil were determined using gas a GC puls-2010 coupled with GCMS-QP2010 (Shimadzu, Japan), which was fitted with a DB-5MS polar column $[30 \mathrm{~mm} \times 0.25 \mathrm{~mm}$ (inner diameter) $\times 0.25 \mathrm{~mm}]$. The temperature program started at $70^{\circ} \mathrm{C}$ for $1 \mathrm{~min}$ and increased to $250^{\circ} \mathrm{C}$ at $6^{\circ} \mathrm{C} / \mathrm{min}$, and then held for $4 \mathrm{~min}$. The injected sample volume was $1 \mu \mathrm{L}$ with a split ratio of 20:1. The mass detector was fitted with an electron ionization source operated at $70 \mathrm{eV}$ with a source temperature of $255^{\circ} \mathrm{C}$. Helium was the carrier gas at a flow rate of $1 \mathrm{~mL} / \mathrm{min}$. Identification of active compounds was based on the mass spectral information in a mass spectra library (Wiley Registry of Mass Spectra Data, 2000), and sample peaks were confirmed by the retention indices (RI) and mass spectra.

\section{Molecular Docking}

Although the plant had antimicrobial activity against all the microorganisms taken for study notable results were obtained for Pseudomonas aeruginosa. This gram negative bacterium with its versatile adaptability has evolved into an opportunistic pathogen prevalent in the immune compromised individuals. Further these organisms circumvent the huge antimicrobial arsenal by way of gaining resistance. Considering the severity of the infection and high adaptivity of the organism, looking for an alternative to treat the pathogen is the need of the hour. Henceforth an attempt is made to screen potential molecular targets by in silico approach. ${ }^{16}$ One of the proteins chosen for our study is the Pseudomonas elastase, a common occurrence at the site of infection which plays a key role in proteolytic tissue damage in the host system. They are also found to initiate the biofilm production. ${ }^{17}$ The second protein chosen for the study was tyrosine phosphatase, a protein that connects the extracellular quorum sensing signals to polysaccharide production and biofilm formation ${ }^{18}$ and intervening this would interrupt the signaling cascade. The final protein of our study was the Alkaline protease, an important protein associated with the human gamma interferon degradation and inhibition. The intensity of infections could be much reduced on targeting this protein. ${ }^{19}$

The target proteins were identified and retrieved from the Protein Data Bank (PDB) with PDB id 4QS. The structure of compound that satisfy the Lipinski's rule was obtained from Pubchem database. Binding score of the ligand and the target proteins were calculated and the bonds involved in the interaction were visualized and the residues involved in it were analyzed.

\section{RESULTS AND DISCUSSIONS}

\section{Phytochemical Analysis}

The phytochemical active compounds of Citrus limon leaf extracts were qualitatively analyzed Table 1 . Presence of alkaloids, caffeine, theobromine, anthocyanin, coumarins, carbohydrates, saponins, flavanoids and terpenoids were evaluated. These phytochemicals have been found to possess a wide range of pharmacological activities, which may help in protection against various human diseases. Epidemiological studies reported that flavanoids to have cure of coronary heart disease, whereas saponins to exhibit antibiotic properties and used to treat hypercholesterolemia. Terpenoids are known to show the anti-viral, anti-inflammatory and anti-malarial activities. ${ }^{20,21}$

\section{Antibacterial Activity}

The antibacterial activity of Citrus limon plant extracts and essential oil were tested against four bacterial strain. The bacterial species namely Bacillus subtilis, Brevibacillus brevis, Pseudomonas aeruginosa, and Microvirga aerilata expressed differential sensitivity to the plant extracts as indicated by their zone of inhibitions Table 1. It signifies that the ethanol extract and essential oil of Citrus limon leaves show higher inhibition when compared to ethyl acetate extract. The zone of inhibition was found to be maximum at $100 \mu \mathrm{g}$ of essential oil against Microvirga

\section{Table 1: Phytochemical Screening of Citrus Plant Extracts}

\begin{tabular}{cccc}
\hline S.NO & PHYTOCHEMICALS & $\begin{array}{c}\text { ETHYL ACETATE } \\
\text { EXTRACT }\end{array}$ & ETHANOL EXTRACT \\
\hline 1. & Alkaloids & + & ++ \\
2. & Caffeine & - & - \\
3. & Theobromine & - & - \\
4. & Anthocyanins & ++ & + \\
5. & Coumarins & - & + \\
6. & Carbohydrates & - & - \\
7. & Saponins & + & - \\
8. & Triterpenoids & - & + \\
9. & Flavanoids & + & + \\
10. & Tannins & + & + \\
\hline
\end{tabular}

(+) Indicates the presence; (-) Indicates the absence 
Table 2: Antibacterial Activity

\begin{tabular}{|c|c|c|c|c|c|c|c|c|c|c|c|c|c|c|c|c|}
\hline \multirow{2}{*}{ S.N } & \multirow{2}{*}{ ORGANISM } & \multicolumn{5}{|c|}{ ESSENTIAL OILS $(\mu \mathrm{l})$} & \multicolumn{5}{|c|}{ ETHANOLIC EXTRACT $(\mu \mathrm{g})$} & \multicolumn{5}{|c|}{ ETHYL ACETATE EXTRACT $(\mu \mathrm{g})$} \\
\hline & & - & 25 & 50 & 75 & 100 & - & 25 & 50 & 75 & 100 & - & 25 & 50 & 75 & 100 \\
\hline 1. & Bacillus subtilis & - & - & - & - & - & - & - & 2 & 3 & 5 & - & - & - & - & - \\
\hline 2. & $\begin{array}{c}\text { Brevibacillus } \\
\text { brevis }\end{array}$ & 3 & 2 & 5 & 5 & 4 & 3 & - & - & 2 & - & - & - & - & 2 & 3 \\
\hline 3. & $\begin{array}{l}\text { Microvirga } \\
\text { aerilata }\end{array}$ & 7 & - & 5 & 9 & 19 & - & - & 3 & 6 & 7 & - & - & - & - & - \\
\hline 4 & $\begin{array}{c}\text { Pseudomonas } \\
\text { aeruginosa }\end{array}$ & 4 & 2 & 6 & 6 & 7 & 4 & 6 & 10 & 5 & - & - & 5 & 7 & 8 & 5 \\
\hline
\end{tabular}

(-) Indicates no inhibition, (+ve) Indicates positive control (Gentamicin), (-ve) Indicates negative control (solvent)

Table 3: Minimum Inhibitory Concentration of Ethanol Extract of Citrus Limon Leaves

\begin{tabular}{|c|c|c|c|c|c|c|c|c|c|c|c|}
\hline \multirow{2}{*}{ S.NO } & \multirow{2}{*}{ BACTERIA } & \multicolumn{10}{|c|}{ CONCENTRATION $(\mu \mathrm{g} / \mathrm{mL})$} \\
\hline & & Extract & 20 & 40 & 60 & 80 & 100 & 120 & 140 & 160 & 180 \\
\hline \multirow[t]{2}{*}{1.} & Brevibacillus brevis & $\mathrm{EE}$ & - & + & + & + & + & + & + & + & + \\
\hline & & E.oil & - & - & + & + & + & + & + & + & + \\
\hline \multirow[t]{2}{*}{2.} & Bacillus subtilis & $\mathrm{EE}$ & - & - & - & - & + & + & + & + & + \\
\hline & & E.oil & - & - & - & - & - & + & + & + & + \\
\hline \multirow[t]{2}{*}{3.} & Microvirga aerilata & $\mathrm{EE}$ & - & - & - & - & - & + & + & + & + \\
\hline & & E.oil & - & - & - & + & + & + & + & + & + \\
\hline \multirow[t]{2}{*}{4.} & Pseudomonas aeruginosa & $\mathrm{EE}$ & + & + & + & + & + & + & + & + & + \\
\hline & & E.oil & - & - & + & + & + & + & + & + & + \\
\hline
\end{tabular}

EE - ethanol extract, E.oil - essential oil, + - Presence, (-) Indicates Absence

aerilata whereas for ethanol extract the inhibition was maximum at $50 \mu \mathrm{g}$ concentration against Pseudomonas aeruginosa. Ethyl acetate extract exhibited very less inhibition against Pseudomonas aeruginosa and Brevibacillus brevis and also no activity was shown against Bacillus subtilis and Microvirga aerilata. In case of essential oil, good inhibitory activity was found against all the organisms except Bacillus subtilis. Present study indicated that the essential oil of leaves of Citrus limon plant showed effective antibacterial activity. Similar observations on the broad spectrum activity of the essential oil from the citrus peel of orange, sweet lime and lemon were reported against food borne pathogens Escherichia coli, Staphylococcus aureus, Salmonella typhi, Shigella species and Candida albicans. ${ }^{22}$

\section{Determination Of Minimum Inhibitory Concentration}

The minimum inhibitory concentration (MIC) of the ethanol extract and essential oil of Citrus limon leaves for four different organisms with different concentration ranged between 20 and $180 \mu \mathrm{g} / \mathrm{mL}$ was determined. Minimum inhibitory concentration varied for each bacterium depending on the solvent and concentration. The minimum inhibitory concentration of the ethanol extract and essential oil of Citrus limon leaves against the bacterial species like Bacillus subtilis, Brevibacillus brevis, Microvirga aerilata and Pseudomonasa aeruginosa is depicted in the Table 3. From the results obtained, it was shown that the minimum inhibitory concentration of the ethanol extract against Pseudomonas aeruginosa, Brevibacillus brevis, Bacillus subtilis and Microvirga aerilata was found to be $20 \mu \mathrm{g}, 80 \mu \mathrm{g}, 60 \mu \mathrm{g}$ and $100 \mu \mathrm{g}$ respectively. In case of essential oil, the MIC was found to be $20 \mu \mathrm{g}$ for Pseudomonas aeruginosa, $40 \mu \mathrm{g}$ for Brevibacillus brevis, $60 \mu \mathrm{g}$ for Microvirga aerilata and $120 \mu \mathrm{g}$ for Bacillus subtilis.

\section{Radical Scavenging Activity}

The result showed that essential oil of the leaves of Citrus limon exhibited high anti-oxidant potential when compared to the ethanol and ethyl acetate extracts of Citrus limon leaves. Figure 1. Thus it was suggested to be used as a supplementary product to combat the degenerative effects resulting from the oxidative stress. ${ }^{23}$

\section{Cytotoxicity Analysis}

The plot between the cell viability in the Y-axis and concentration in the $\mathrm{X}$ - axis indicates significant reduction in the cell viability of HeLa cells. The $\mathrm{IC}_{50}$ values were determined as $4.75 \mu \mathrm{g}$ for essential oil, $3.09 \mu \mathrm{g}$ for ethyl acetate extract and $5.15 \mu \mathrm{g}$ for ethanol extract. Cytotoxicity of both the extracts and essential oil appeared to be active at the concentration of $50 \mu \mathrm{g} / \mathrm{mL}$ and $100 \mu \mathrm{g} / \mathrm{mL}$. Essential oil of Citrus limon leaves showed better cytotoxic activity compared to the other two extracts (Figure 2). The current observations on the activity of the extracts reveal that they

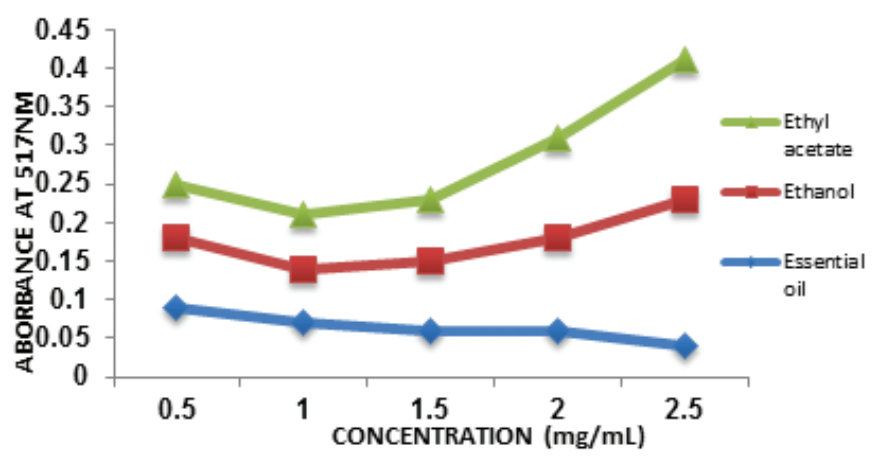

Figure 1: Radical Scavenging Activity of Essential Oil, Ethyl Acetate and Ethanol Extracts Of Citrus limon Leaves. 


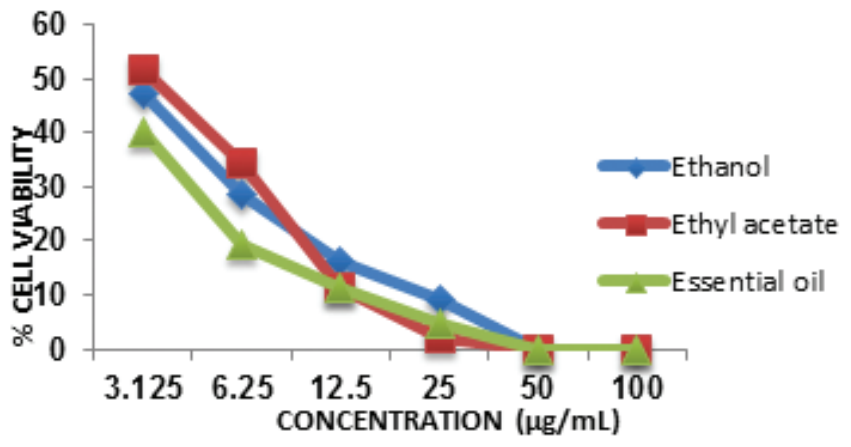

Figure 2: Cytotoxicity of the Extracts and Essential Oil of Citrus limon Leaves.

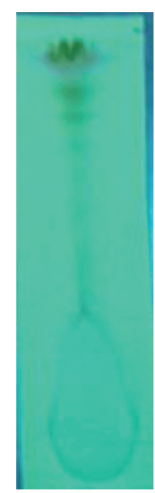

a) $\mathrm{EE}$

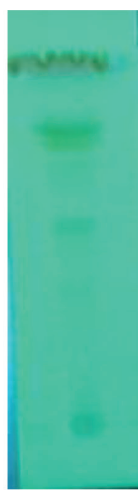

b) EA c) EO

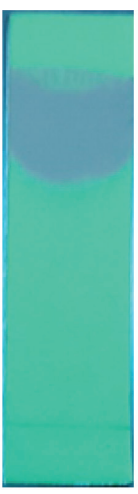

d) $\mathrm{EE}$
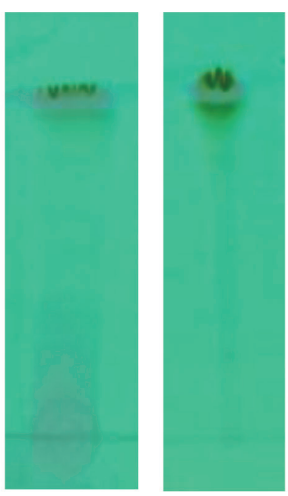

e) EA

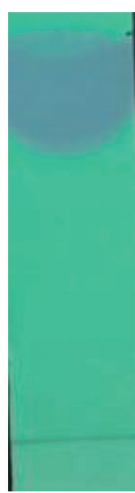

f) $\mathrm{EO}$
Figure 3: Thin Layer Chromatography of Essential Oil, Ethyl Acetate and Ethanolic Extracts of Citrus limon using solvent system I (Acetone: Chloroform) (a-c) Solvent System II (Ethyl Acetate: Acetone) (d-f).. EE - Ethanol extract, EA - Ethyl acetate extract, EO - Essential oil.

are dose dependent. It is encouraging to note that the plant has pronounced antioxidant activity which in a way could be a better choice to alleviate the worse effects of free radical mediated cellular damage to the cell control mechanism. More importantly various part of this plant material is consumed in many parts of the world, thereby making it more convenient to introduce the benefits of the plant metabolites in the day to day diet. However differential activity towards the normal and cancer lines is an inevitable requirement of a successful chemotherapeutic agent. Henceforth more toxicity based studied to assess the safety and efficacy of the molecule should be concentrated in the later part of the work. Similar reports on the cytotoxicity effect of Citrus limon essential oil was reported against HeLa cell lines. ${ }^{24}$

\section{Thin Layer Chromatography}

TLC analysis of the ethyl acetate extract, ethanol extract and essential oil of Citrus limon leaves revealed the presence of active compounds that were visualized in UV. On the combination of Acetone: Chloroform (solvent system I) the extract resolved to six and seven bands for the ethanol and ethyl acetate extract. When the two different extracts are separated by the solvent system II (Acetone: Ethyl acetate), four bands were separated for ethanol extract and six bands for ethyl acetate. Essential oil of solvent system I and solvent system II exhibited a range of $R_{f}$ values between 0.6491 and $0.9123,0.6935$ and 0.9677 respectively. The $\mathrm{R}_{\mathrm{f}}$ values of all the three samples are depicted in the Table 4 . These separated bands indicated the presence of active molecules that are present in the leaves of lemon. The visualized bands are given in the Figure 3.

\section{GAS Chromatography MASS Spectrometry AnalySIS}

Limon leaf extracts prepared in ethanol and essential oil extracted by hydro-distillation, when analyzed using GCMS shows the presence of following compounds as shown in Figure 4 a \& b. Identification of the components was carried out by comparison of their spectra with standard spectra in the NIST Library (Wiley). Relative percentage of each component of the essential oil was obtained according to the surface area of the corresponding peak on GC chromatogram by normalizing of the surface. The results showed that 4,9-Dimethoxy-7h-Furo[3,2-G]Chro (29.27\%) and 7H-Furo[3-2 g][1]benzophyren-7-one (29.20\%) were the major component of ethanol extract of Citrus limon leaves whereas $2 \mathrm{H}$ Benzocyclohepten-2-one (68.02\%), 1,6-Octadiene,7-Methyl-3-Dimethyl (7.17\%) and 1,3,7-Octatriene,3,7-Dimethyl (7.29\%) were the significant components of Citrus limon essential oil. Few chemical components of Citrus limon essential oil identified in this study was found to be similar with previous reports of Indian and Turkish essential oil of Citrus limon. ${ }^{23}$ Such components include $\alpha$-pinene, $\beta$-pinene, decanal, citral and $\alpha$-terpineol. These compounds that are identified by GCMS analysis are the bioactive molecules that may be responsible for effective antibacterial and anticancer activity.

\section{Molecular Docking}

The plant extracts and essential oil of Citrus limon when tested for antibacterial studies gave significant inhibition for Pseudomonas aeruginosa compared to all the other organisms henceforth the in silico studies was planned through molecular docking analysis with discovery studio 2.0 version. The level of inhibition of ligands with the bacterial target protein was identified by GCMS analysis and also through supporting literature studies.

The proteins namely tyrosine phosphatase, alkaline protease, and elastase from Pseudomonas aeruginosa were our selected molecular targets and

Table: 4 Retention Factors of Two Different Extracts and Essential Oil in Solvent System I \& II

\begin{tabular}{ccccccc}
\hline & \multicolumn{5}{c}{ RETENTION FACTOR VALUES } \\
\cline { 2 - 7 } BANDS & \multicolumn{3}{c}{ SOLVENT SYSTEM I } \\
\cline { 2 - 7 } & Ethanol extract & $\begin{array}{c}\text { Ethyl acetate } \\
\text { extract }\end{array}$ & Essential oil & $\begin{array}{c}\text { Ethanol } \\
\text { extract }\end{array}$ & $\begin{array}{c}\text { Ethyl acetate } \\
\text { extract }\end{array}$ & Essential oil \\
\cline { 2 - 7 } 1 & 0.2941 & 0.3333 & 0.6491 & 0.8070 & 0.7719 & 0.6935 \\
2 & 0.7059 & 0.5185 & 0.9123 & 0.8421 & 0.8246 & 0.9677 \\
3 & 0.7647 & 0.6852 & & 0.8772 & 0.8596 & \\
4 & 0.7941 & 0.7407 & & 0.9649 & 0.8772 & \\
5 & 0.8382 & 0.7777 & & - & 0.9123 \\
6 & 0.9559 & 0.7963 & & 0.9561 \\
7
\end{tabular}



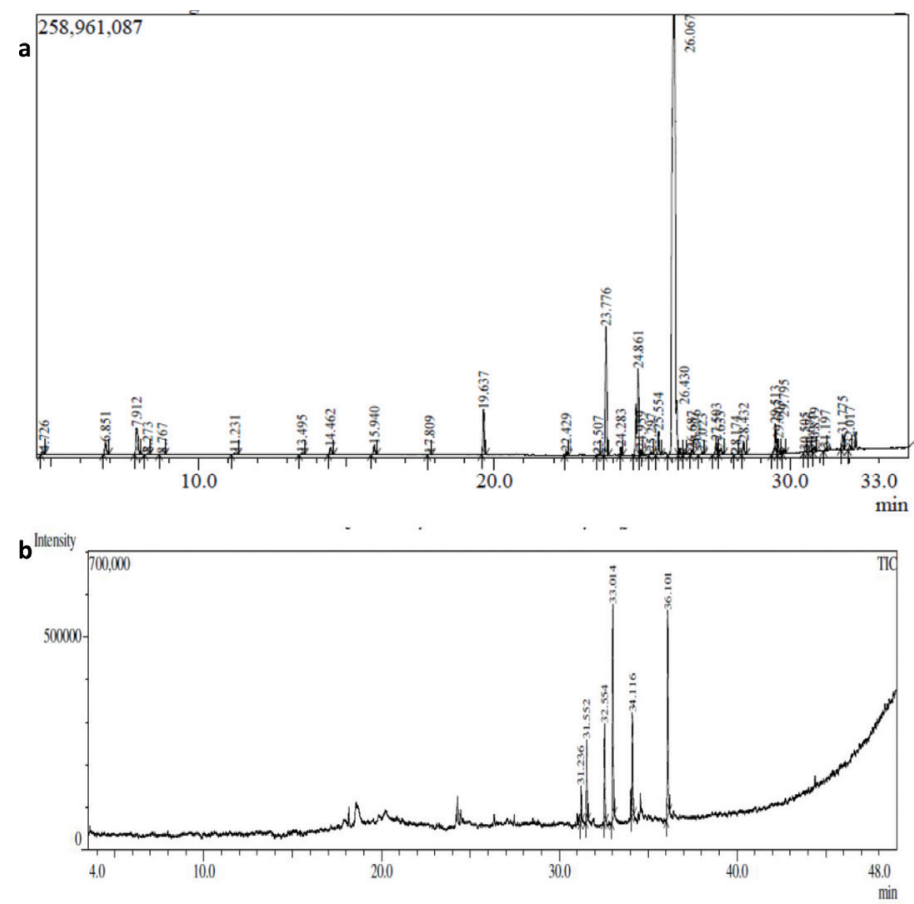

Figure 4: a)Chromatogram of Essential Oil of Citrus limon Leaves by GCMS Analysis b) Chromatogram of Ethanol Extract of Citrus limon Leaves by GCMS Analysis.

inhibition was checked for all the three proteins among which tyrosine phosphatase showed better interaction than the other two proteins. Hence tyrosine phosphatase was studied in detail to check the bondings, bond distances and atoms occurring between the protein and ligand. Eight binding sites were initially located for tyrosine phosphatase. Of the 14 compounds taken for the study methoxsalen, methacrolein and 2, 6- octadienal had better interactions at active site 3 and 1. These compounds showing good interactions were analyzed based on the bonds, bond distances, atoms, dock scores and other scoring values. ${ }^{24-30}$

Methoxsalen having the compound id 4114 shows better binding than the other compounds. The table shows the order of high to low interacting compounds which is decided based on ligand 1, 2, plp1, 2, pmf, jain, internal energy and dock score values. The ligand 1 and ligand 2 scores show the affinity of the ligand and plp1 and plp2 values, pmf, jain all these are scoring functions used to calculate the interaction energy. Thus the best three compounds are analyzed and listed below.

The Figure $5 \mathrm{a}$ and $\mathrm{b}$ shows the interaction between the ligand - Methoxsalen and the protein tyrosine phosphatase and the bonds, bond distance involved between them. The green dotted lines show the hydrogen bonding between the protein and the ligand, this bonding happens at the position of (ARG96) arginine residue, and the atoms involved at this interaction are $\mathrm{H} 22$ and $\mathrm{O} 4$. The distance between this bonding is measured as $2.3 \mathrm{~A}^{\circ}$. The other bonds involved are pi-alkyl interactions, and conventional interactions. The pi-alkyl interaction shows distance of $4.98 \mathrm{~A}^{\circ}$. The ligand 1 score of 1.85 , ligand 2 score of 3.5 , plp1 value of 47.72 and plp2 value of 34.94 , pmf value of 28.9 and the dock score of 27.099 with -2908 internal energy was obtained. Thus the compound 4114 shows good interaction and good dock score were obtained, showing the compound inhibits the protein well. The Figure $5 \mathrm{~b}$ shows the hydrogen bond acceptor and hydrogen bond donors and how the ligand is set inside the cavity. The green patches present denote the hydrogen bond acceptor and the purple patches represent the hydrogen bond donor, and it shows how the ligand is present inside the cavity
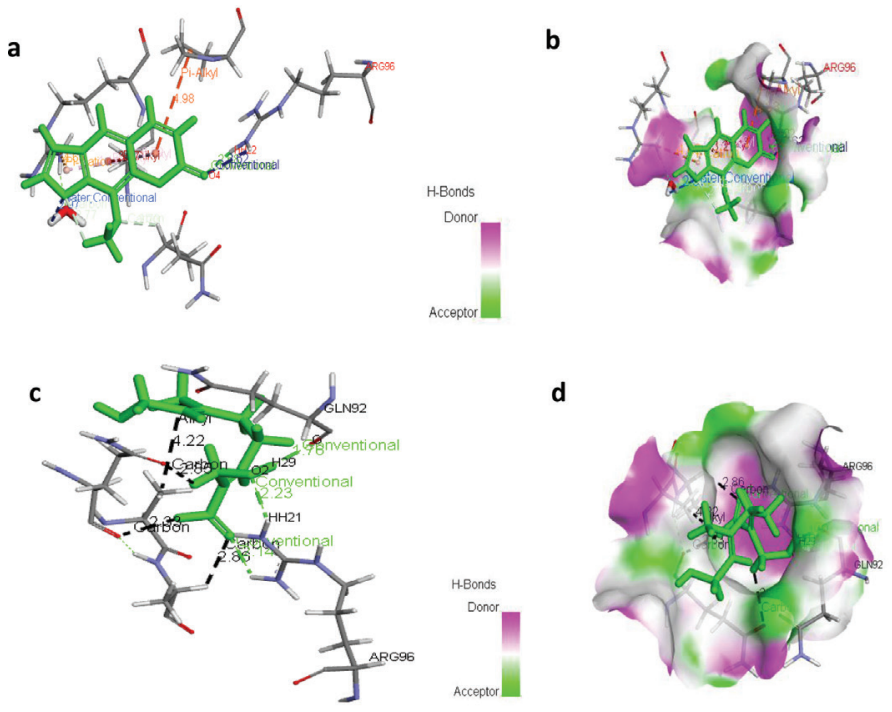

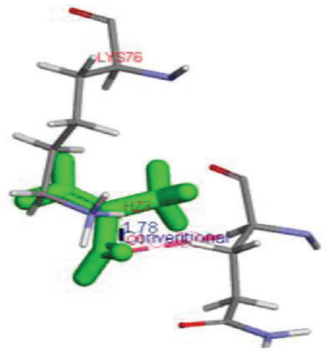

f

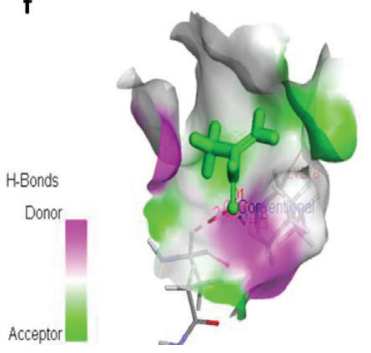

Figure 5: a) Interactions between the Target Protein and the Ligand Methoxsalen (compound- 4114) b) Hydrogen Bond Donors and Acceptors between the Target Protein and the Ligand Methoxsalen (Compound-4114) c) Interactions between the Target Protein and the Ligand 2, 6-octadienal (Compound-71318515) d) Hydrogen Bond Donors and Acceptors between the Target Protein and the Ligand 2, 6-Octadienal (Compound-71318515) e) Interactions between the Target Protein and the Ligand Methacrolein (Compound-6562) f) Hydrogen Bond Donors and Acceptors between the Target Protein and the Ligand Methacrolein (Compound-6562).

The Figure $5 c$ shows the interaction between the ligand and the protein and the bonds, bond distance involved between them. The green dotted lines show the hydrogen bonding between the protein and the ligand, this bonding happens at the position of GLN92 residue and ARG96, and the atoms involved at this interaction are $\mathrm{H} 29, \mathrm{O} 2$ and $\mathrm{HH} 21$. The distance between this bonding is measured as $1.98 \mathrm{~A}^{\circ}$ and $2.23 \mathrm{~A}^{0}$ respectively. The other bonds involved are pi-alkyl interactions, carbon and conventional. This compound shows good interaction with ligand 1 value of 1.64, ligand 2 value of 2.98 , plp1 value of 29.42, plp2 value of 25.21 , pmf value of 28.54 and dock score of 19.260 with an internal energy of -1.53 thus showing good interaction with the protein.

The Figure 5d shows the hydrogen bond acceptor and hydrogen bond donors and how the ligand is set inside the cavity. The green patches present denote the hydrogen bond acceptor and the purple patches represent the hydrogen bond donor, and it shows how the ligand is present inside the cavity.

The Figure 5e shows the interaction between the ligand and the protein and the bonds, bond distance involved between them. The green dotted lines shows the hydrogen bonding between the protein and the ligand, this bonding happens at the position of lys76 residue and the atoms involved at this interaction are $\mathrm{Hz} 3$ and si. The distance between this 
bonding is measured as $1.78 \mathrm{~A}^{\circ}$. The other bonds involved are carbon interactions and conventional.

This compound shows good interaction with ligand 1 value of 1.31 , ligand 2 value of 2.64, plp1 value of 21.28, plp2 value of 20.69 , pmf value of 4.81 and dock score of 19.017 with an internal energy of -0.119 thus showing good interaction with the protein.

The Figure $5 f$ shows the hydrogen bond acceptor and hydrogen bond donors and how the ligand is set inside the cavity. The green patches present denote the hydrogen bond acceptor and the purple patches represent the hydrogen bond donor and it shows how the ligand is present inside the cavity. These in vivo studies show that the protein tyrosine phosphatase as a better molecular target that could be chosen for further studies. Further from the docking studies we could infer that methoxsalen could interfere with the target protein. This molecule should be characterized and studied for its toxicity profile which could be a potential drug target.

\section{CONCLUSION}

Essential oil and ethanol extract of Citrus limon was found to antibacterial activity against Microvirga aerilata and Pseudomonas aeruginosa at $100 \mu \mathrm{g}$ and $50 \mu \mathrm{g}$ respectively. Both the crude extract and essential oil were found to have anticancer activity against HeLa cell at the concentration of $50 \mu \mathrm{g} / \mathrm{mL}$ and $100 \mu \mathrm{g} / \mathrm{mL}$ respectively. GCMS analysis of essential oil confirmed the presence of $\alpha$-pinene, $\beta$-pinene, decanal, citral and $\alpha$-terpineol. Molecular docking studies against tyrosine phosphatase, alkaline protease, and elastase of Pseudomonas aeruginosa revealed that the compounds of Citrus limon to interact with tyrosine phosphatase better than the other two proteins.

\section{ACKNOWLEDGEMENT}

We sincerely acknowledge Sathyabama University for providing us all facility to carry this work.

\section{CONFLICT OF INTEREST}

We have no conflict of interest.

\section{ABBREVIATION USED}

EE: Ethanol extract; EA: Ethyl acetate extract; EO: Essential oil.

\section{REFERENCES}

1. Chanthaphon S, Chanthachum S, Hongpattarakere T. Antimicrobial activities of essential oils and crude extracts from tropical Citrus spp. against food-related microorganisms. Songklanakarin J Sci Technol. 2007;30(1):125-31.

2. Morton JF. Lemon in Fruits of Warm Climates, Purdue University. 1987;160-8.

3. Park K, Park H, Kimb M, Hong G, Nagappan A, Lee H, et al. Flavonoids identified from Korean Citrus aurantium L. inhibit Non-Small Cell Lung Cancer growth in vivo and in vitro. J Fun Foods. 2014;7:287-97.

4. Pandey A, Kaushik A, Tiwari SK. Evaluation of antimicrobial activity and phytochemical analysis of Citrus limon. J Pharm Biomed Sci. 2011;13:1-7.

5. Akhila S, Bindu AR, Bindu K, Aleykutty NA. Comparative Evaluation of Extracts of Citrus limon Burm Peel for Antioxidant Activity. J Young Pharm. 2009;1(2):136-40.

6. Adepoju G, Adeyemi T. Evaluation of the effect of lime fruit juice on the anticoagulant effect of warfarin. J Young Pharm. 2010;2(3):269-72.

7. Lawal OA, Ogunwande AI, Owolabi SM, Giwa-Ajeniya AO, Kasali AA, Abudu AF, et al. Comparative analysis of essential oils of Citrus aurantifolia Swingle and Citrus reticulata Blanco, from two different localities of Lagos State, Nigeria. Am J Ess Oils Nat Prod. 2014;2(2):08-12.
8. Harborne AJ. Phytochemical Methods A Guide to Modern Techniques of Plant Analysis, Thomas Science Publication. 1998.

9. Parasuraman S, Sankar N, Chandrasekar T, Murugesh K, Neelaveni T. Phytochemical analysis and oral hypoglycemic activity of leaf extract of leaves of Andrographis stenophylla C.B. Clarke (Acanthaceae). Int J Appl Biol Pharm Tech. 2010;1(2):442-8.

10. Rahman A, Shanta ZS, Rashid MA, Parvin T, Afrin S, Khatun MK, et al. In vitro antibacterial properties of essential oil and organic extracts of Premnaintegri folia Linn. Arabian Journal of Chemistry. 2011;10:10-6.

11. Shekhar TC, Anju G. Antioxidant Activity by DPPH Radical Scavenging Method of Ageratum conyzoides Linn. Leaves, Am J Ethnomed. 2014;1:244-9.

12. Brand W, Cuvelier ME, Berset C. Use of free radical method to evaluate antioxidant activity. Lebenson Wiss Technol. 1995;28(1):25-30.

13. Mosmann T. Rapid Colorimetric Assay for Cellular Growth and Survival: Application to Proliferation and Cytotoxicity Assays. J Immunol Methods. 1983; 65(1-2):55-63.

14. Bhulabhai PJ. Anticancer and cytotoxic potential of aqueous extract of Triticum aestivum on HeLa cell lines. J Drug Deli Ther. 2016;6(3):84-9

15. Verma A, Ahirwar AK. Phytochemical Investigations, Extraction and Thin Layer Chromatography of Acorus Calamus Linn. Int J Res Stu Biosci. 2015;3:18-22.

16. Gellatly SL, Hancock RE. Pseudomonas aeruginosa: new insights into pathogenesis and host defenses. Pathogens and Disease. 2013;2049-632

17. Cathcart GRA, Quinn D, Greer B, Harriott P, Lynas JF, Gilmore BF, et al. Novel Inhibitors of the Pseudomonas aeruginosa Virulence Factor LasB: a Potential Therapeutic Approach for the Attenuation of Virulence Mechanisms in Pseudomonal Infection, Antimicrob Agents Chemother. 2011;55(6):2670-8.

18. Ueda A, Wood TK. Connecting Quorum Sensing, c-di-GMP, Pel Polysaccharide, and Biofilm Formation in Pseudomonas aeruginosa through Tyrosine Phosphatase TpbA (PA3885). PLoS Pathogens. 2009;5(6).

19. Palamthodi SM, Gaikwad VJ, Nitin VG, Patil SS. Antibacterial targets in Pseudomonas aeruginosa. Inter J Pharm App. 2011;2(3):159-64.

20. Wadood A, Ghufran M, Jamal SB, Naeem M, Khan A et al. Phytochemical Analysis of Medicinal Plants Occuring in Local Area of Mardan. Biochem and Biochem. 2013;2.

21. Zhang YJ, Gan RY, Li S, Zhou Y, Li AN, Xu DP, Li HB. Antioxidant Phytochemicals for the Prevention and Treatment of Chronic Diseases. Molecules. 2015; 20(12):21138-56.

22. Hasija S, Ibrahim G, Wadia A. Antimicrobial Activity of Citrus Sinensis (Orange), Citrus Limetta (Sweet Lime) and Citrus Limon (Lemon) Peel Oil on Selected Food Borne Pathogens. Inter J Life Sci Res. 2015;3:35-39.

23. Fidrianny I, Harnovi M, Insanu M. Evaluation of antioxidant activities from various extracts of sweet orange peels using DPPH, FRAP assays and correlation with phenolic, flavonoid, carotenoid content. Asian J Pharm Clin Res. 2014;7(3):186-190.

24. Huang $\mathrm{C}, \mathrm{Pu} \mathrm{H}$, Zhang ZJ. Song, Evaluation of antioxidant and antitumour activities of lemon essential oil. J Medicinal Plants Res. 2010;4(8):1910-5

25. Nasser NNA, Mohammad AH. Comparative chemical composition and antimicrobial activity study of essential oils from two imported lemon fruits samples against pathogenic bacteria. Beni-Suef Unv J Basic and Applied Sci. 2014;3(4):247-53.

26. Lingala S, Nerella R, Enaganti S. Synthesis and Molecular Docking Studies of Novel Benzimidazole Derivatives as Human Cyclin Dependent Kinase-2 Inhibitors. World Jf Pharm Pharm Sci. 2013;3:453-65

27. Gowthaman U, Jayakanthan M, Sundar D. Molecular Docking Studies of Dithionitrobenzoic acid and its Related Compounds to Proteins Disulfide Isomerase: Computational Screening of Inhibitors to HIV-1 Entry. BMC Bioinformatics. 2013.

28. Hamsa NS, Nair VP, Chandramohan V, Patel SJ. Pharmacophore Elucidation and Docking Studies on Anti-Inflammatory Compounds of Medicinal Plants for Ulcerative Colitis. Asian J Pharm Clin Res. 2013;6(3):56-61.

29. Rizvi D, Shakil S, Haneef M. A Simple Click Protocol to Perform Docking: Autodock 4.2 Made Easy for Non-Bioinformaticians. EXCLI Journal. 2013;831-57.

30. Barik MR, Ranjan S. Molecular Docking and High-Throughput Screening of Potent Inhibitor to gp46SU Involved in ATLL through Drug Design Studies. J Chem Pharm Res. 2012;4(6):3040-6.

Article History: Submission Date: 11-10-16; Received Date: 02-01-17; Acceptance Date: 21-01-17.

Cite this article: Raji P, Samrot AV, Dharani D, Alexander B. In vitro and In silico Approaches to Study the Bioactivity of Citrus limon Leaf Extracts. J Young Pharm. 2017;9(2):290-5 